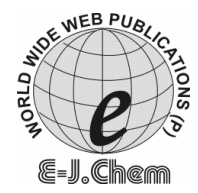

http://www.e-journals.net
ISSN: 0973-4945; CODEN ECJHAO

E-Journal of Chemistry 2010, 7(3), 669-676

\title{
Removal of Dyes from Aqueous Solution by Adsorption on Biomass of Mango (Mangifera Indica) Leaves
}

\author{
T. MURUGAN, A. GANAPATHI and R. VALLIAPPAN ${ }^{*}$
}

Department of Chemistry, Faculty of Engineering and Technology, ${ }^{*}$ Chemistry Wing, DDE, Annamalai University, Annamalai Nagar- 608 002, Tamilnadu, India.

Received 16 November 2009; Accepted 10 January 2010

\begin{abstract}
The potential feasibility of mango leaves powder (MLP) (Mangifera indica) for removal of dye (Grey BL) from aqueous solution was investigated. The effects of various experimental parameters were examined and optimal experimental conditions were decided. Above the value of initial $\mathrm{pH} 7$, the dye studied could be removed effectively. The isothermal data fitted the Langmuir model or Freundlich model. The adsorption processes followed the pseudo-first-order rate kinetics. The results in this study indicated that mango leaf powder (MLP) was an attractive candidate for removing dye from dye wastewater.
\end{abstract}

Keywords: Adsorption, Grey BL dye, Mango leaves powder.

\section{Introduction}

Water is life. Sustainability of any human community hinges on adequate supply of potable water, which confirms to the acceptable standard, at a price that is affordable to all. This makes process economy a paramount factor in the treatment of water and wastewater. Consequent upon this, the need to eliminate the existing paradox between the cost of water treatment, which is very high and potable water price, which is very low, is imminent.

Dyes usually have a synthetic origin and complex aromatic molecular structures, which make them more stable and more difficult to biodegrade ${ }^{1}$. Today there are more than 10,000 dyes available commercially ${ }^{2}$. Dyes are widely used in textiles, paper, rubber, plastics, leather, cosmetics, pharmaceutical and food industries. The extensive use of dyes often poses pollution problems in the form of colored wastewater discharged into environmental 
water bodies. It not only affects aesthetic merit but also reduces light penetration and photosynthesis. In addition, some dyes are either toxic or mutagenic and carcinogenic ${ }^{3}$. The conventional methods for treating dyes containing wastewaters are coagulation and flocculation ${ }^{4}$, oxidation or ozonation ${ }^{5,6}$, membrane separation ${ }^{7}$ and activated carbon adsorption ${ }^{8}$ But these technologies do not show significant effectiveness or economic advantage. Activated car bon is the most popular and widely used dye sorbent but there are certain problems with its use. It is expensive and the higher the quality the greater the cost. Furthermore, regeneration using solutions produces a small additional effluent, while regeneration by refractory technique results in a $10-15 \%$ loss of sorbent and its uptake capacity. Therefore, there is a growing interest in using low cost, easily available biomaterials for the adsorption of dye colors. Some low cost botanic materials had directly been used as sorbent for dye adsorption from wastewater ${ }^{9-20}$. As the largest producer of synthetic dyes and developing nation in the world, new, economical and highly effective treatment technologies of dye wastewater were urgently needed in India.

In this paper, the feasibility of mango leaves powder (MLP) as sorbent for removal of dye from aqueous solution was investigated. Mango tree is a plant belongs to the family anacardiaceae (Mangifera indica) is an evergreen plant, which is extensively cultured in India. The annual mango output of India is 5 million tons and an estimated total of 2.0 million ton of mango leaves is produced annually. Most of this agricultural waste is arbitrarily discarded or set on fire. These disposals must result in environmental pollution. The exploitation and utilization of this bioresource must bring obvious economic and social benefit to us.

The dye selected as sorbate was Grey BL, $\left(\lambda_{\max }=575 \mathrm{~nm}\right)$. The effects of various operating parameters on adsorption such as sorbent dosage, particle size, contact time, initial dye concentration and $\mathrm{pH}$ were monitored and optimal experimental conditions were decided.

\section{Experimental}

The biomass (Mango leaves) used in this study was collected from local fields. The collected biomaterial was extensively washed with tap water to remove soil and dust, sprayed with distilled water then dried in an oven at $80^{\circ} \mathrm{C}$ to a constant weight. Dry mango leaves was crushed into powder and sieved to different particle sizes, then preserved in the desiccator for use.

\section{Preparation of dye solution}

The dye (Grey BL), in commercial purity, was used without further purification. The dye stock solutions were prepared by dissolving accurately weighted dye in distilled water to the concentration of $1000 \mathrm{mg} / \mathrm{L}$. The experimental solutions were obtained by diluting the dye stock solutions in accurate proportions to different initial concentrations.

\section{Experimental methods and measurements}

Adsorption experiments were carried out in a rotary shaker at $150 \mathrm{rpm}$ and $27{ }^{\circ} \mathrm{C}$ using $250 \mathrm{~mL}$ shaking flasks containing $100 \mathrm{~mL}$ different concentrations and initial $\mathrm{pH}$ values of dye solutions. The initial $\mathrm{pH}$ values of the solutions were previous adjusted with $0.1 \mathrm{M} \mathrm{HNO}_{3}$ or $\mathrm{NaOH}$ using $\mathrm{pH}$ meter. Different doses of sorbent were added to each flask. After shaking 
the flasks for predetermined time intervals, the samples were withdrawn from the flasks and the dye solutions were separated from the sorbent by filtration then centrifugation. Dye concentrations in the supernatant solutions were estimated by measuring adsorbance at maximum wavelengths of dyes with a $752 \mathrm{~W}$ Grating Spectrophotometer (Avatar, India) and computing from the calibration curves. The experiments were conducted in duplicate and the negative controls (with no sorbent) were simultaneously carried out to ensure that adsorption was by mango leaves powder (MLP) biomass and not by the container.

\section{Results and Discussion}

\section{Effect of sorbent dose}

The effects of sorbent dose on the removal ratios of dyes are shown Figure 1. The percentages of dyes sorbed increased as the sorbent dose was increased over the range 0.1-1.5 g/L. The adsorption ratios of dyes increased from 25.00 to $63.07 \%$, Grey BL. Above $1.5 \mathrm{~g} / \mathrm{L}$ of sorbent dose, the adsorption equilibrium of dye was reached and the removal ratios of dye held almost no variety. So, the mango leaves biomass of $1.0 \mathrm{~g} / \mathrm{L}$ was chosen for subsequent experiments.

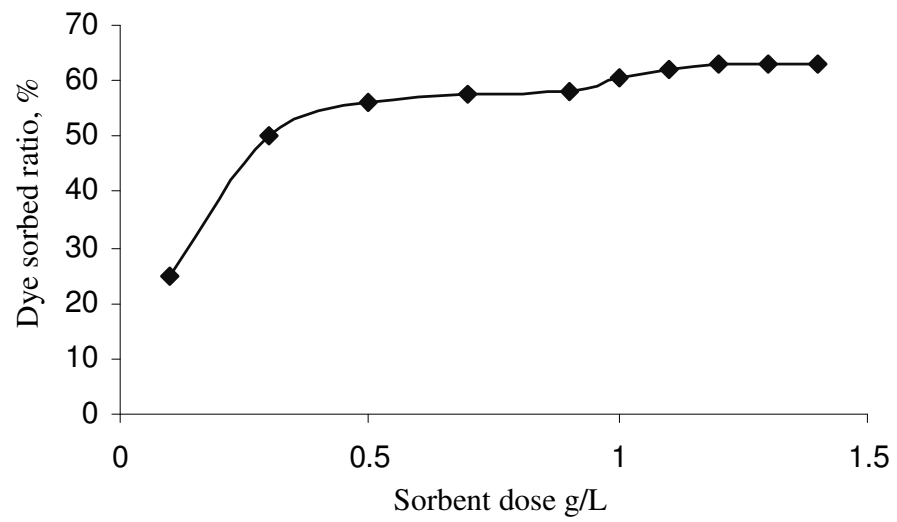

Figure 1. Effect of sorbent dose on adsorption of Grey BL by mango leaves powder (MLP) (dye concentration: $100 \mathrm{mg} / \mathrm{L}$; particle size: $400 \mu$ contact time: $5 \mathrm{~h}$; pH 7.0).

\section{Influence of initial dye concentration}

The initial concentration provides an important driving force to overcome all mass transfer resistance of dye anions between the aqueous and solid phases. In addition, increasing initial dye concentration increases the number of interactions between dye anions and sorbent, which enhances the sorption process. Hence a higher initial concentration of Grey BL will increase the biosorption rate. The effect of initial dye concentration on the dye sorption capacity of dried mango leaves powder biomass was investigated between 50 and $1000 \mathrm{mg} \mathrm{L}^{-1}$. The graphical representation of the dependence of the retained amount of dye versus time is given by single and continuous curves, which proves the formation of a monolayer at the external surface of the sorbent. For Grey BL the equilibrium is attained in 120-180 min depending on the investigated concentrations. When the dye concentration was increased from 50 to $500 \mathrm{mg} / \mathrm{L}$, the percentage of dyes sorbed decreased. The sorption is very fast initially. It was observed that depending on concentration, the dye is retained after $15 \mathrm{~min}$ time of contact with the sorbent (Figure 2). 


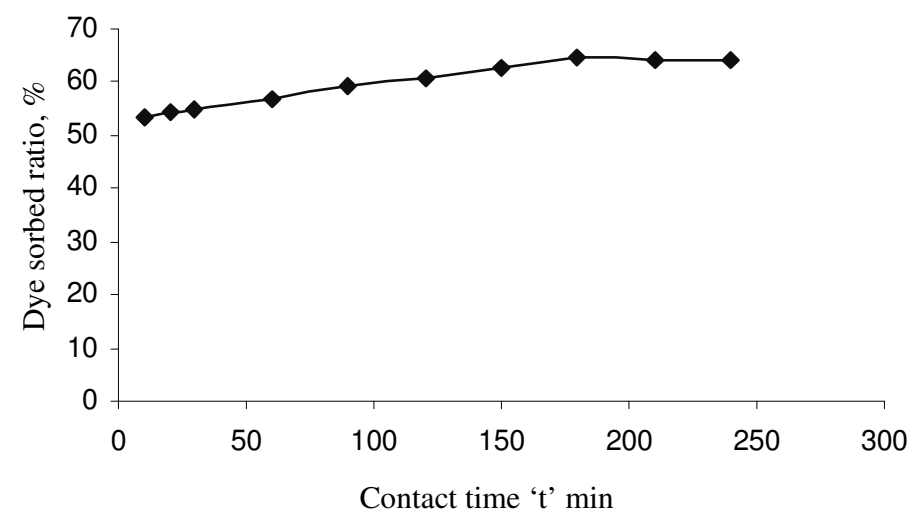

Figure 2. Influence of dye concentration on adsorption of Grey BL by mango leaves (sorbent dose: $100 \mathrm{mg} / \mathrm{L}$; particle size: $400 \mu$; contact time: $5 \mathrm{~h}$; $\mathrm{pH} 7.0$ ).

\section{Effect of initial $\mathrm{pH}$}

An important influencing factor for dye biosorption on agricultural by-products has been referred to $\mathrm{pH}$ as in most studies published in the literature. The effects of initial $\mathrm{pH}$ on adsorption percentages of dyes were researched over a range of $\mathrm{pH}$ values from 2 to 10 . As elucidated in Figure 3, for the dye Grey BL, the dye removal ratio was minimum at the initial $\mathrm{pH}$ 2. The ratio of dye sorbed increased as the initial $\mathrm{pH}$ was increased from $\mathrm{pH} 2$ to 7 , then the dye removal ratios were not significantly altered $(P>0.05)$ beyond $\mathrm{pH} 8$. From the Figure 3 , it is observed that in the $\mathrm{pH}$ range of 7-8, the $\mathrm{pH}$ biomass adsorbs to the extent of $64.25 \%$ of the colouring matter. Hence in all the studies an optimum $\mathrm{pH}$ of 7.0 is used.

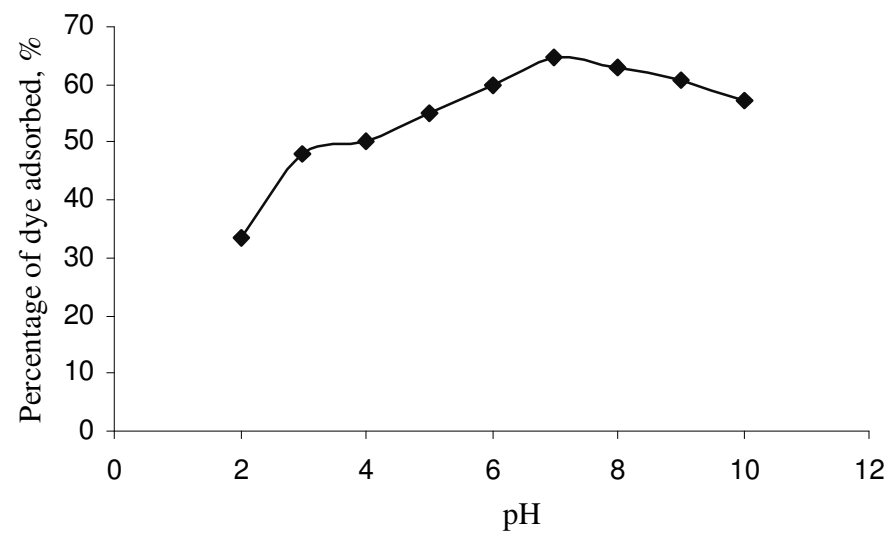

Figure 3. Effect of initial $\mathrm{pH}$ on adsorption of Grey BL by mango leaves (dye concentration: $100 \mathrm{mg} / \mathrm{L}$; sorbent dose: $1 \mathrm{~g} / \mathrm{L}$; particle size: $400 \mu$, contact time: $5 \mathrm{~h}$; Temperature $300 \mathrm{~K}$ ).

Adsorption isotherm

Adsorption isotherms are prerequisites to understand the nature of the interaction between adsorbate and the adsrobent used for the removal or organic pollutants ${ }^{21}$. In the present study, the adsorption of Grey BL on MLP (Figure 4) shows that the adsorption of the dye increases with increase in dye concentration and tends to attain saturation at higher concentrations. The experimental data have also been analyzed by two well-known adsorption isotherm models Langmuuir (Equation-1) and Freundlich (Equation- 2). 


$$
\frac{C e}{q_{e}}=\frac{1}{K_{L}}+\frac{a_{L} C_{e}}{K_{L}}
$$

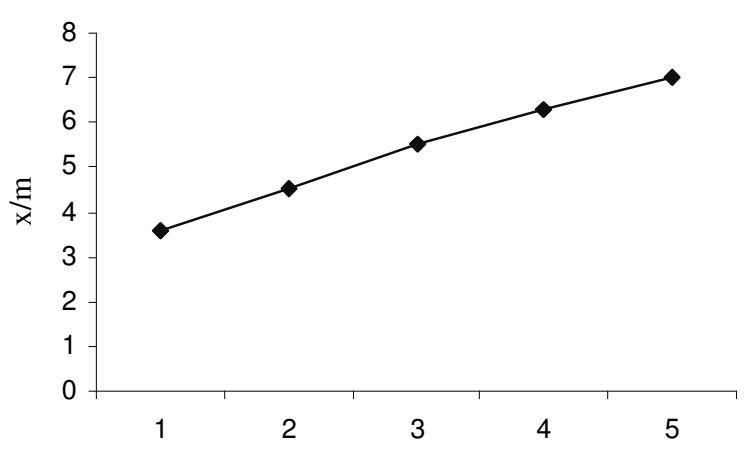

Equilibrium dye concentration, $\mathrm{mg} / \mathrm{L}$

Figure 4. Equilibrium adsorption of Grey BL.

Where $C$ e and $q$ e are the equilibrium dye concentration in the solution $(\mathrm{mg} / \mathrm{L})$ and on MLP $(\mathrm{mg} / \mathrm{g})$, respectively, $a_{\mathrm{L}}$ and $K_{\mathrm{L}}$ are the Langmuir constants. Figure 5 shows that adsorption of Grey BL fits well to the Langmuir isotherm model with a correlation coefficient of 0.998 , supporting monolayer coverage of the adsorbate on the surface of adsorbent. The theoretical monolayer saturation capacities of MLP have been calculated to be $33.7 \mathrm{mg} / \mathrm{g}(0.051 \mathrm{mmol} / \mathrm{g})$. This value is higher to that of other biosorbents such as $\mathrm{GAC}^{22}$, coir pith ${ }^{23}, \mathrm{PAC}^{22}$, banana pill and orange pill ${ }^{24}$. However, adsorption capacity of neem leaf powder ${ }^{25,26}$ and waste coir pith $^{27}$, respectively, towards Grey BL is higher to a small extent.

Langmuir equation can also be used to obtain, $R_{\mathrm{L}}$, the dimensionless equilibrium parameter or the separation factor from the expression:

$$
R L=\frac{1}{1+a_{L} C_{o}}
$$

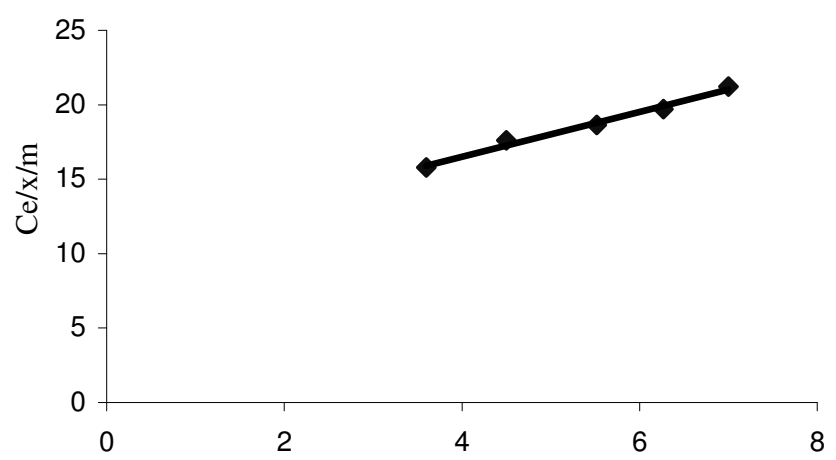

Equilibrium dye conceration, $\mathrm{mg} / \mathrm{L}$

Figure 5. Langmuir plots for the adsorption of Grey BL. 
Where $C_{0}$ is the initial concentration of the adsorbate and $a_{\mathrm{L}}$ is the Langmuir coefficient as described above. The value of $R_{\mathrm{L}}$ has been determined to be 0.050 for Grey BL, for an initial dye concentration of $250 \mathrm{mg} / \mathrm{L}$ indicating that the adsorption process is favourable. The data was also analyzed by the Linearized form of Freundlich isotherm model

$$
\log q_{e}=\log K_{F}+\frac{1}{n \log C_{e}}
$$

Where $C_{\mathrm{e}}$ and $q_{\mathrm{e}}$ are the equilibrium concentration of dyes in the solution $(\mathrm{mg} / \mathrm{L})$ and on MLP (mg/g), respectively. $K_{\mathrm{F}}$ is the Freundlich constant and $1 / n$ is the heterogeneity factor. The Figure 6 shows that Freundlich model also fits for Grey BL (correlation coefficient 0.997) adsorption process.

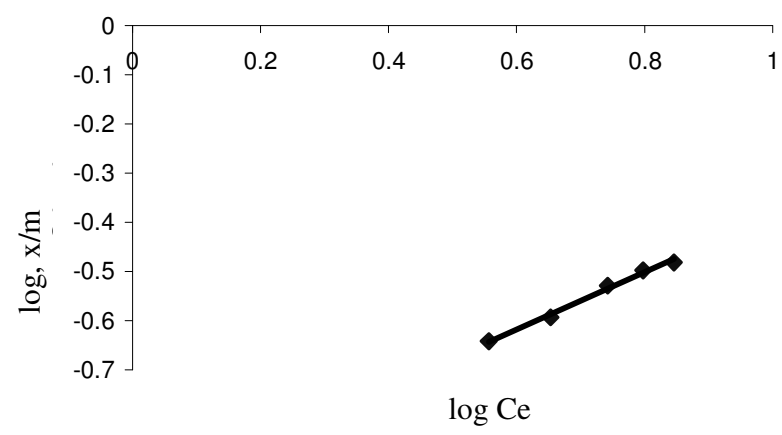

Figure 6. Freundlich plots for the adsorption of Grey BL.

\section{Adsorption kinetics}

The rate as well as mechanism of adsorption process can be elucidated on the basis of kinetic study. Dye adsorption on solid surface may be explained by two distinct mechanisms; (i) an initial rapid binding of dye molecules on the adsorbent surface followed by (ii) relatively slow intra-particle diffusion. Progress of the adsorption of dyes by MLP with agitation time (Figure 7) shows that the rate of adsorption of the dye molecules was initially very fast and then gradually slows down to reach equilibrium within $1 \mathrm{~h}$. To determine the rate controlling and mass transfer mechanism, experimental kinetic data were correlated to linear form of the pseudo first- and second-order (Eq. $3 \& 4$ ) rate models.

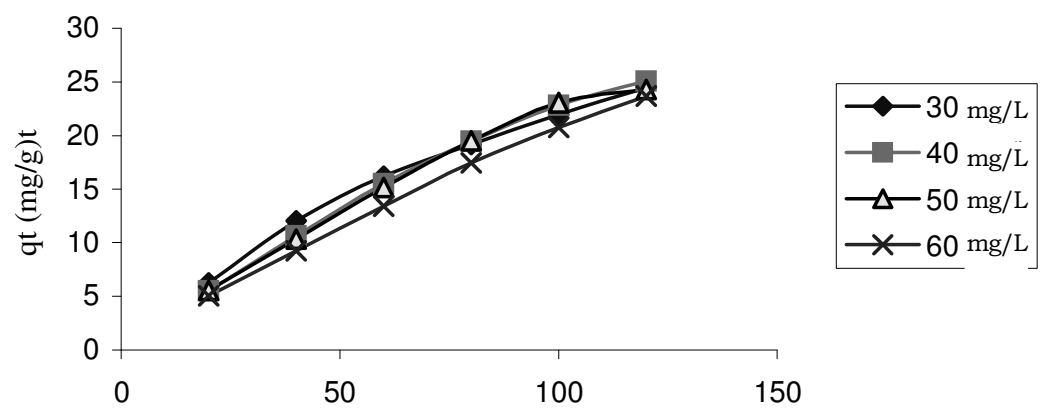

Time, $t, \min$

Figure 7. Elovich plot - effect of contact time on Grey BL by MLP biomass 


$$
\begin{gathered}
\log \left(q_{e}-q_{t}\right)=\log q_{e}-\frac{K_{1} t}{2.303} \\
\frac{t}{q_{t}}=\frac{1}{k_{2} q_{e}^{2}}+\frac{t}{q_{e}}
\end{gathered}
$$

Where $q \mathrm{e}$ is the equilibrium concentration, $t$ is the time, $k_{1}$ and $k_{2}$ are the first- and second-order rate constants, respectively; $q t$ is the uptake per gram of MLP biomass at time $t$. On the other hand, linearity (Figure 8$)$ with high correlation coefficients ( 0.999 for Grey BL dye) indicates that the present sorption process follows second-order rate model (Figure 9). Transportation of the dyes from the solution phase into the pores of the adsorbent may also be considered as the rate controlling stage in batch experiments under rapid stirring condition.

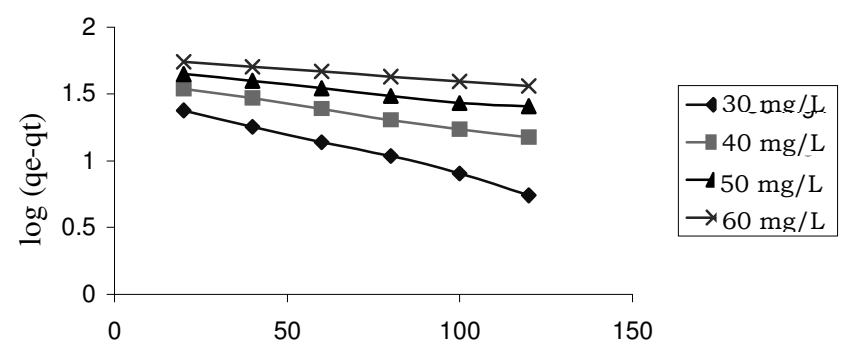

Time, $\mathrm{t}, \mathrm{min}$

Figure 8. First order plot - initial Grey BL concentration variation.

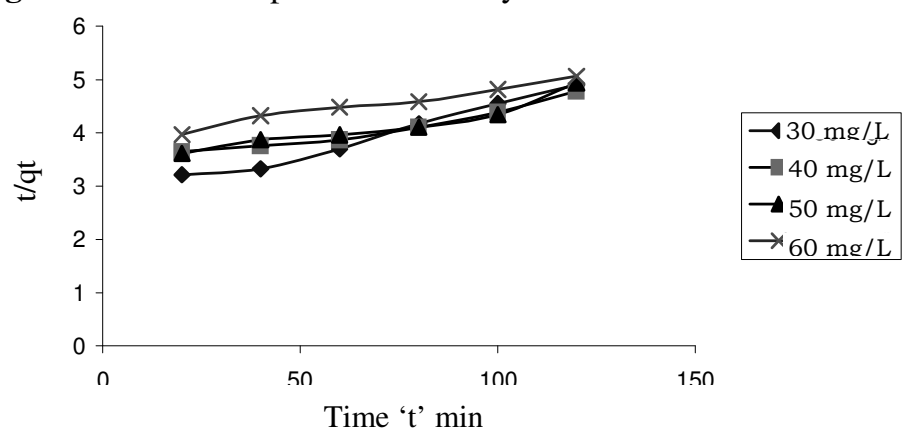

Figure 9. Pseudo-second-order plot of adsorption of Grey BL dye concentration variation. SEM of adsorbent

The Figure 10 shows the SEM micrographs of MLP samples before dye adsorption. It shows that the MLP possesses a rough surface morphology with pores of different sizes. These pores are useful for dye adsorption.

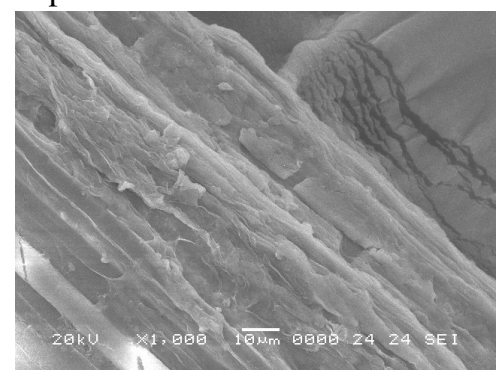

Figure 10. SEM micrograph of MLP (magnification: 1000x) before dye adsorption. 


\section{Conclusion}

This study showed that mango leaf powder particle (MLP) could effectively remove Grey $\mathrm{BL}$ from aqueous solution. The optimal $\mathrm{pH}$ for favorable adsorption of dyes was 7 and above. The percentages of dyes sorbed increased then reached maximum values as the sorbent dose was increased. The adsorption equilibrium was reached at about $12 \mathrm{~h}$. The isothermal data fitted the Langmuir model or Freundlich model. The adsorption processes followed the pseudo-first-order rate kinetics.

\section{Acknowledgments}

The authors were grateful to the Professor and Head, Department of Chemistry and the authorities of the Annamalai University to perform research work.

\section{References}

1. Seshadri S, Bishop P L and Agha A M, Waste Manage, 1994, 15, 127-137.

2. Nigam P, Armour G, Banat I M, Singh D and Marchant R, Biores Technol., 2000, 72 , 219-226.

3. Chen K C, Wu J Y, Huang C C, Liang Y M and Hwang S C J, J Biotechnol., 2003, 101, 241-252.

4. $\quad$ Panswed J and Wongchaisuwan S, Water Sci Technol., 1986, 18, 139-144.

5. Malik P K and Saha S K, Sep Purif Technol., 2003, 31, 241-250.

6. Koch M, Yediler A, Lienert D, Insel G and Kettrup A, Chemosphere., 2002, 46, 109-113.

7. Ciardelli G, Corsi L and Marucci M, Resour Conserv Recy., 2000, 31, 189-197.

8. Venkata R B and Sastray C A, Ind J Environ Prot., 1987, 7, 363-376.

9. Robinson T, Chandran B and Nigam P, Water Res., 2002, 36, 2824-2830.

10. Namasivayam C, Muniasamy N, Gayatri K, Rani M and Ranganathan K, Bioresour Technol., 1996, 57, 37-43.

11. Robinson T, Chandran B and Nigam P, Bioresour Technol., 2002, 85, 119-124.

12. Nassar M M, Hamoda M F and Radwan G H, Water Sci Technol., 1995, 32, 27-32.

13. Nassar M M, Water Sci Technol., 1999, 40, 133-139.

14. Garg V K, Gupta R, Yadav A B and Kumar R, Bioresour Technol., 2003, 89, 121-124.

15. Morais L C, Freitas O M, Goncalves E P, Vasconcelos L T and Beca C G G, Water Res., 1999, 33, 979-988.

16. Bhattacharyya K G and Sarma A, Dyes and Pigments, 2003, 57, 211-222.

17. Namasivayam C and Kadirvelu K, Bioresour Technol., 1994, 48, 79-81.

18. Namasivayam C, Prabha D and Kumutha M, Bioresour Technol., 1998, 64, 77-79.

19. McKay G, El Geundi E and Nassar M M, Process Safety Environ., 1996, 74, 487-502.

20. Low K S, Lee C K and Tan K K, Bioresour Technol., 1995, 52, 79-83.

21. Aksu Z, Process Biochem., 2005, 40, 997-1025.

22. Fu Y and Vijayaraghavan T, Adv Environ Res., 2004, 7, 239-247.

23. Namasivayam C, Radhika R and Suba S, Waste Manage., 2001, 21, 381-387.

24. Annadurai G, Juang R and Lee D, J Hazard Mater., 2002, B 92, 263-274.

25. Bhattacharyya K G and Sharma A, J Environ Manage, 2004, 71, 217-229.

26. Krishna G Bhattacharyya and Arunima Sharma, Dyes and Pigments, 2005, 65: 51-59.

27. Namasivayam C, Kumar M D, Salvi K, Beum R A, Vanathi T and Yamuna R T, Biomass Bioenergy, 2001, 21, 477- 483. 


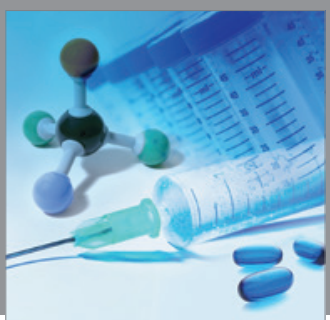

International Journal of

Medicinal Chemistry

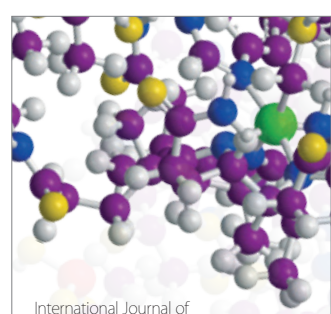

Carbohydrate Chemistry

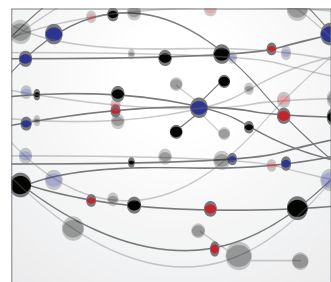

The Scientific World Journal
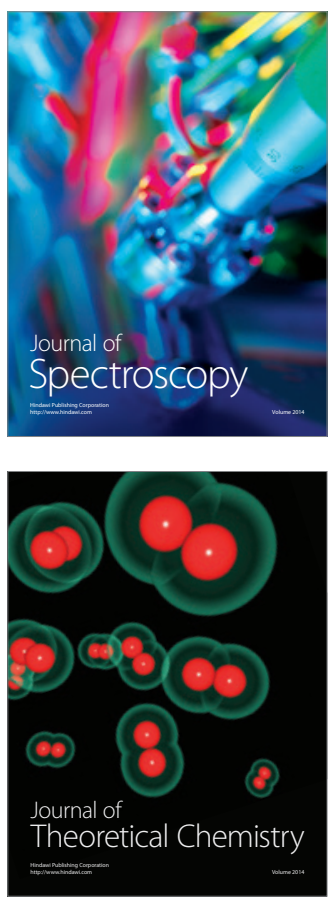
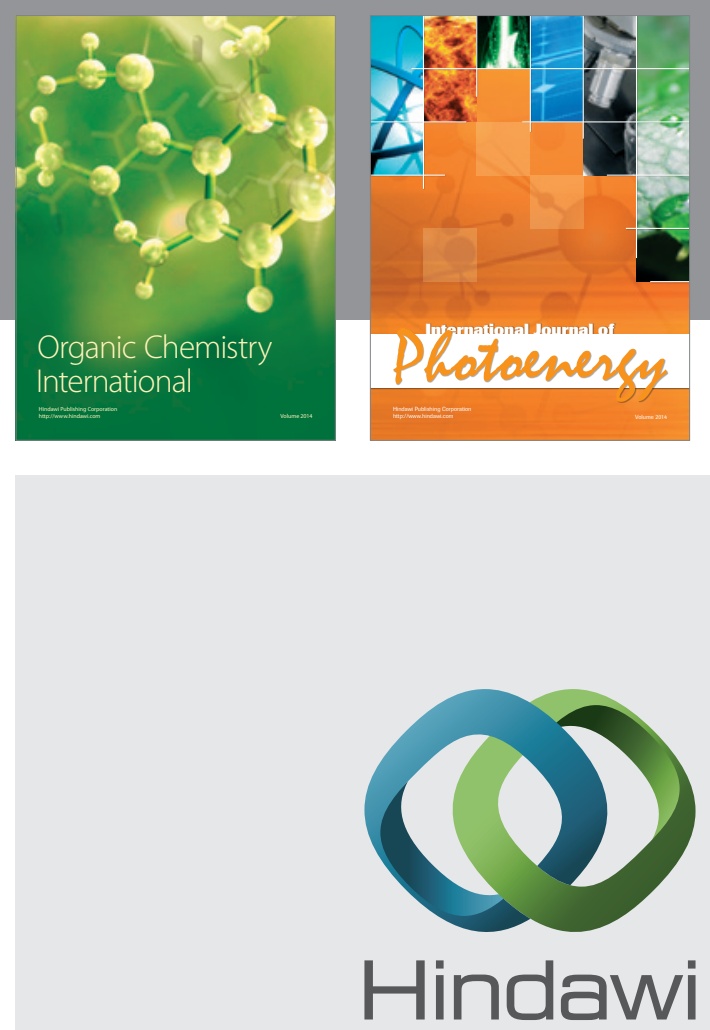

Submit your manuscripts at

http://www.hindawi.com
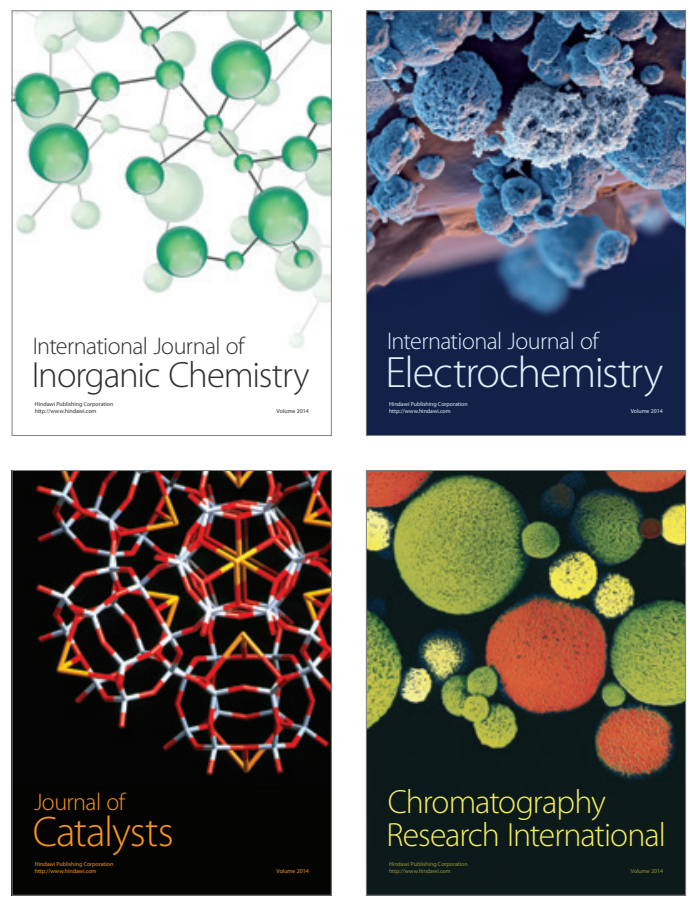
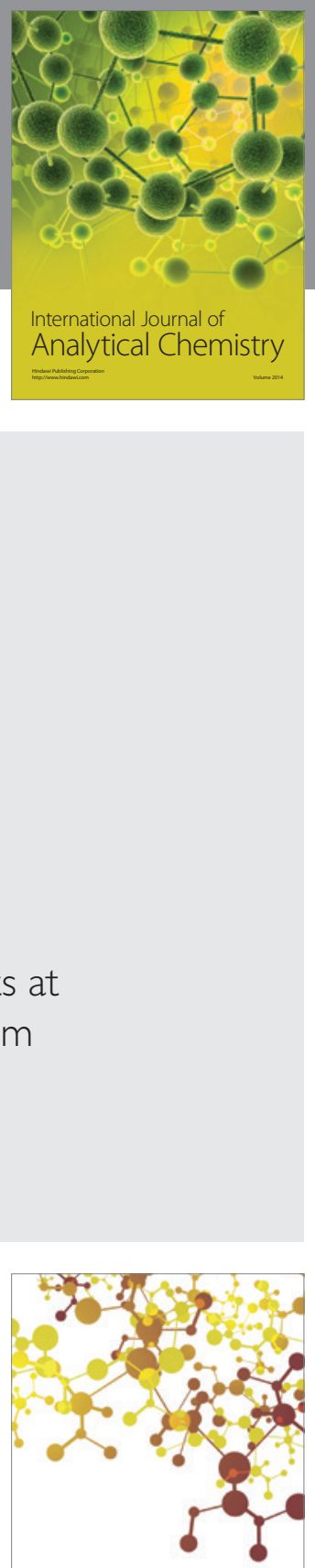

Journal of

Applied Chemistry
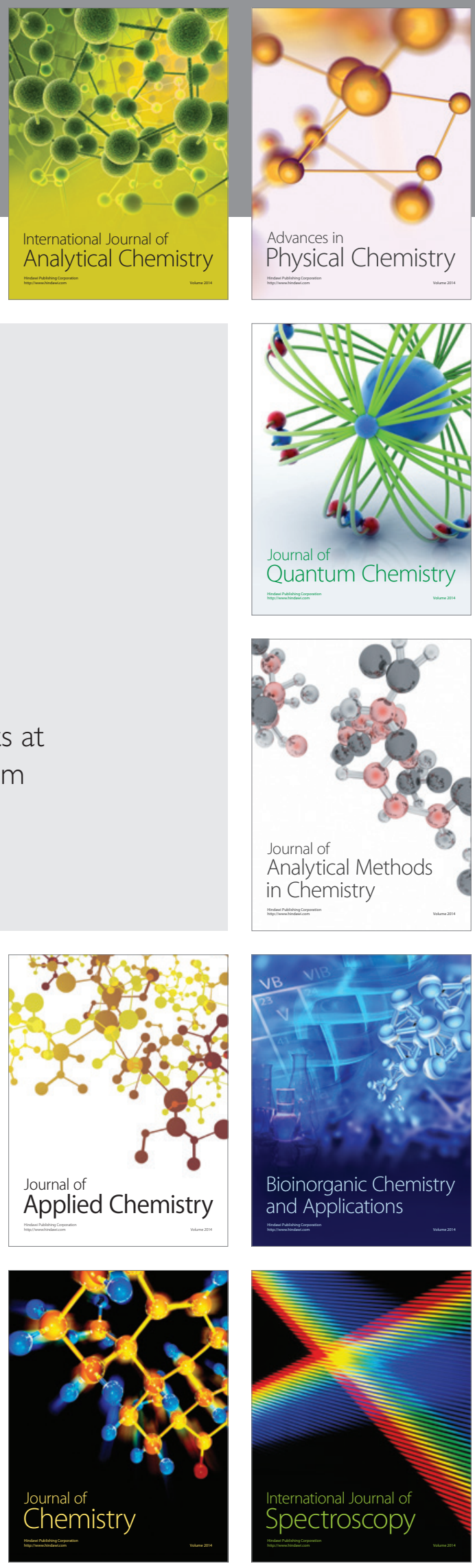